\title{
The Collection in a New Light - Towards Visual Exploration and Navigation of Academic Library Resources
}

\author{
Hugo Huurdeman, Mikaela Aamodt, Kyrre Traavik Låberg \& Dan Michael Heggø \\ hugo@timelessfuture.com, mikaela.aamodt@ub.uio.no, k.t.laberg@ub.uio.no, d.m.heggo@ub.uio.no \\ University of Oslo Library
}

This is an Accepted Manuscript of an article published by Taylor \& Francis in International

Information \& Library Review on 24 Dec 2018, available online:

http://www.tandfonline.com/10.1080/10572317.2018.1491704.

\begin{abstract}
The current experience of using digital libraries is bereft of many of the distinct qualities of exploring and handling items in the physical library space. The main question addressed in this paper is how to bridge the gap between the highly visual experience of browsing physical libraries, and the comparatively impoverished digital library environments. Creating effective applications integrating digital content in physical library spaces requires careful strategies with respect to user experience, content selection, and connections to real-world collections and events. We show collection-centric, event-centric and integrative approaches to creating touch-based applications, and demonstrate how usage data from touch applications can be used for optimization, as well as for inspiration for new applications.
\end{abstract}

\section{Introduction}

Our information environment has changed rapidly in the past decades. Where physical libraries were once the prime source for academic publications, now the digital environment plays a pivotal role. Journals and their articles are available digitally now, and there is an ever increasing number of e-books. These materials are easily acquired, usually just being a few clicks away via library systems and even common search engines. However, the gradual decline of physical access to books, journals and other academic library resources also leads to a loss: in many ways, the digital environments are impoverished as compared to their physical counterparts (Pomerantz \& Marchionini, 2007). On the one hand, there is a loss of the physical sense of being immersed in a world of books (Blandford, Rimmer, \& Warwick, 2006), and on the other hand a severe loss of browsing opportunities.

The loss of physical browsing opportunities may limit open-ended explorations, as well as serendipitous encounters with information. Physical library environments often invite their user to "move, explore and browse" (Björneborn, 2008), but also to "stop, touch and assess" materials encountered on the way. In contrast, digital libraries have increasingly evolved to the Google-style paradigm of a single search box, with a single list of results and some faceted filters (Huurdeman \& Kamps, 2014). Despite a variety of projects aiming to achieve more inclusive browsing experiences (e.g. Kleiner, Rädle, \& Reiterer, 2013; Thudt, Hinrichs, \& Carpendale, 2012; Pearce \& Chang, 2014), digital library environments have so far not been able to replicate this experience (McKay, Chang, \& Smith, 2017). The failure to take up more exploratory approaches may be related to the fact that it is not straightforward to effectively translate the physical browsing experience into the digital realm. 
Hence, there is still a gap between the highly visual experience of browsing physical libraries, and the affordances of their digital counterparts. The main question addressed in this paper is how to bridge this gap. Within the Visual Navigation Project (2016-2018), conducted at the University of Oslo Library, we have explored new ways to offer more inclusive experiences. We used physical opportunities as inspiration for digital tools, and digital tools as inspirations to enrich the physical library space. Thus, we may move beyond traditional catalog approaches and towards more inclusive ways to integrate the physical and the digital. This paper discusses previous literature, exploratory studies done within the project, as well as three approaches for integrating touch-based applications into a physical library setting. Also, we describe how the data generated from both physical and digital resource usage can be used to evaluate and improve tools in the various library environments. Finally, we reflect on learned lessons about designing and developing touch applications in the discussion section.

\section{Previous Literature}

Over the years, a variety of authors have described the importance of the physical surroundings of libraries. For instance, libraries have served as repositories for large collections of publications, as places for contemplation and study, and as a social space (Blandford et al., 2006). Physical libraries can inspire because of their spatial properties (Pomerantz \& Marchionini, 2007) and invite users to explore, browse and touch items (Björneborn, 2008). As indicated by Blandford et al. (2006), the "physical sense of being surrounded by, even immersed in, books creates a sense of possibilities, of serendipity where discoveries can be made, apparently by accident". This serendipity may be facilitated by such aspects as unhampered access to resources, diversity of content, curiosity-teasing displays, pointers, and even imperfections ("cracks and loopholes in library interfaces"), as Björneborn (2008) has argued. On a more abstract level, Pomerantz and Marchionini (2007) discuss the "physical-conceptual continuum" occupied by libraries, ranging from the actual physical reality one is in, to places existing in our minds. Libraries are "places that marry physical space with intellectual space, to link people to ideas and to each other" (p.506).

When discussing the current physical library space, Björneborn (2008) distinguishes between human library resources (e.g. staff, users, invited lecturers), physical resources (materials, such as books, journals, CDs, and display devices such as shelves and tables), and digital resources (resources using screens, and digital display devices, including catalogs, databases, internet). Björneborn's holistic conceptual framework (or 'integrative interface') connects these resources and incorporates "the totality of all contact surfaces, access points and mediation flows between users and available library resources". A user, upon entering a library, may be encountering and interacting with different library resources in the settings of her own socio-cognitive context (i.e., interests, tasks, problems, needs, intentions). In this view, the different types of digital, human and physical resources are supplementary and supportive of each other.

A good overview of the pivotal elements of physical libraries is essential, since our information environment has been in an age of transformation, with rapidly increasing digitization and computerization in the past decades. This leads Pomerantz and Marchionini (2007) to indicate that nowadays "for many users of a physical library's resources and services, the library's digital component is what they interact with most, or even exclusively" (p.527). The change of emphasis moving from physical to digital libraries results in a loss of traditional means to access collections. 
The "tactile sensation" of handling physical objects, but also serendipity is a valued feature of the physical library (Blandford et al., 2006), that may disappear in digital environments. Even though e-materials offer myriad advantages, as they are searchable, easy to access and portable, there is actually "little scope for serendipitous discovery", as McKay et al. (2017, p.47) indicate. Worse still, "outside a few experimental systems, options for collection understanding are poor". Also, according to McKay et al., "currently no system exists that provides the rich, broad experience of browsing the shelves".

At the moment, the predominant way to mediate between user and information is via search systems. While efficient for lookup tasks, search has inherent limitations for complex and open-ended tasks (Huurdeman \& Kamps, 2014). Also, as phrased by McKay et al. (2017, p.47), "search caters for only a small part of the information seeking process under any circumstances, not just in libraries - yet it is the predominant information interaction paradigm online". There have been developments in the area of exploratory search (Marchionini, 2006; White \& Roth, 2009), but these developments have seldomly led to integration in current library catalogs and discovery systems. As Bates (2007) has indicated, "The design of interactive information systems needs to incorporate an awareness of human browsing characteristics", in particular it should "enable the searcher to manifest the instinctive tendency to engage in a browsing sequence: to glimpse, then to examine or not something glimpsed, then to keep or not the things examined." How to best achieve this in digital system, is still an open question.

In the past, a variety of projects have taken up the challenge of bringing browsing to digital platforms. This includes Kleiner et al. (2013)'s Blended Shelf, targeting to replicate the experience of browsing shelves. This was done via large interactive whiteboards and touch-based displays. Other projects have taken more variant approaches. The Bohemian Bookshelf (Thudt et al., 2012; Hinrichs, 2013) allows for multifaceted visual exploration of library resources, via a range of visualizations, and was installed on a tilted touch screen. The web app Bookfish (Pearce \& Chang, 2014) allows for "Exploration Without Keywords", by using sliders to adjust book selections and was aimed at exploratory browsing by children. Still, these projects have mainly been conducted in research settings, and have not been integrated more permanently in digital libraries or physical libraries.

As McKay et al. (2017) suggest, many previous approaches have not been grounded in a good understanding of reader motivations, intentions in browsing, and the physical process. In fact, directly translating the shelf experience, as some previous projects do, may not be the optimal way forward, since physical shelf browsing in itself is not perfect. First of all, the common approach of showing densely packed shelves, with only back spines visible, may leave less possibilities for serendipitous encounters than "curiosity teasing" display of materials (Björneborn, 2008) by "displaying book covers on tilted shelves". Second, for more focused searches "considerable human effort to access the ideas contained in that place" is required (Pomerantz \& Marchionini, 2007, p.520), and "physical libraries are more prone to temporary disorganisation that disrupts the search than digital libraries are" (Blandford et al., 2006). Third, Waugh, McKay, \& Makri (2017, p.279) have documented a "seeking-encountering tension", which is characterised "by the temptation to explore information beyond an original goal versus the urge to return to this goal". As Björneborn (2008) has argued, based on earlier work by Ford (1999), library users may be engaged in convergent (goal-directed) and divergent (explorative) information behavior. The tension documented by Waugh et al. (2017) can be 
connected to these types of behavior: due to potentially overwhelming amounts of information, users may return to the "safe haven" of goal-directed behavior instead of more explorative approaches.

Thus, the approach to directly replicate shelf browsing in digital systems, as McKay et al. (2017) put it, may be an approach "that offers many of the drawbacks of library shelves without the advantages of physical affordance" (p.48). Based on their user study on library shelf browsing, they provide seven recommendations for digital book browsing systems: Displaying a large range of books for browsing (1), Enabling multiple points of access to the collection (2), Supporting zooming capabilities (3), Seamless transitions between browsing and reading (4), Placemarking support (5), Visual alternatives during triage (selecting and rejecting candidate documents) (6), and Access to relevant book information (7). These recommendations can help to improve the design of future browsing systems. Moreover, McKay, Buchanan, \& Chang $(2015$, p.291) indicate that it is important to look at context-dependent approaches to browsing: "users need to be able to 'grab and go' when it suits them, but browsing facilities should be a visibly tempting way for users to spend any extra time they have."

New types of browsing applications can be devised for digital libraries, but also for integration in physical libraries, for instance by using large touch screens and touch tables. This touches upon earlier work on physical exhibitions, in settings of libraries, museums and archives (including Hinrichs, 2013). Allen and Gutwill (2004) show five pitfalls of physical exhibitions: multiple interactive features of equal priority can overwhelm visitors (1), interactivity by multiple simultaneous users can lead to disruption (2), interactivity, even by a single visitor, can disrupt the phenomenon being displayed (3), and interactive features can make a critical phenomenon difficult to find (4). Also, careful balancing is needed: a secondary interactive feature can displace visitors' attention from the primary one (5). Other aspects to take into account are mentioned by Hinrichs (2013), for instance related to digital exhibitions' "robustness" (in terms of hardware and software), meaning these applications should be stable enough to be used in public environments, and relating to potential superficiality of interactions. Pertaining superficiality, she describes cases where users engage with an installation "for the sake of watching the direct-touch interface react to their interactions" (p.293), without paying attention to the content, but she also observed that playful interactions can raise curiosity and lead to actual in-depth explorations. Thus, careful balancing is needed.

In this paper, we build upon previous studies in the domains of library and information science, as well as human-computer interaction. We use methodologies from library and information science, but also design thinking to elicit ideas and requirements for new approaches to exploration of library resources. Furthermore, we take into account previous recommendations and guidelines with respect to the development of exploratory tools in a library context, and we look at how we can integrate the physical and the digital world to a larger extent, i.e. making the digital more physical and the physical more digital.

\section{Explorative studies on Visual Navigation in Physical and Digital Library Spaces}

The Visual Navigation Project has used qualitative and quantitative methods to gather ideas and elicit requirements. This included four types of explorative studies (summarized in Figure 1): observations in the different libraries of the University of Oslo (UiO), interviews with students visiting the library, $\log$ analysis of previous user queries in the used library discovery system, as well as brainstorms with 
library staff and students. Other studies, not described here, included gigamapping (Sevaldson, 2011) sessions mapping out existing and future technical infrastructure, and brainstorms on technological opportunities. In this section, we outline how the four explorative studies contributed to an enhanced understanding of the physical and digital library space, and of how these spaces are used.

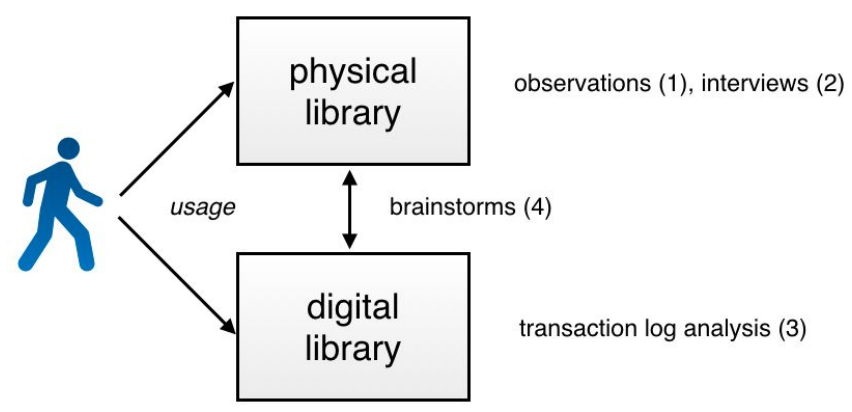

Figure 1: Outline of methods to analyze current usage of the physical and digital library, and to gather ideas for more integration

\section{Observations}

In a library and information science setting, observations can "provide evidence of the 'here and now', to discover how people behave and interact in particular situations" (Pickard, 2007, p. 201). Making observations is a useful method to inform us about common existing interactions between library users and staff at different library branches. The observations were performed by one of the project members in September and October 2016, and took place in four branches of the University of Oslo Library: Science, Informatics, Medical, and Humanities \& Social Sciences Library. The goal of these observations was to get a general idea of the differences and commonalities of interactions between library users and staff. In addition, various types of questions asked by library users were logged. Logged questions included book-related questions (e.g. book requests, pickups, returns), database-related questions, tech questions (e.g. how to install a printer), use of utilities, and questions about room reservations. The observations showed the commonalities of user interactions with library staff in the different branches, as well as the variations in questions asked in the different branches. For instance, there was a higher degree of literature related questions in the Medical Library. For the Medical Library, we also performed a small analysis of email requests, which included books requests, article requests (e.g. "find me the references of page $\mathrm{x}$ of paper $\mathrm{y}$ "), requests for a search session with a librarian, issues with a relation to access to resources, course-related questions, as well as reference software (i.e. Endnote) questions. The fact that there were differences in the types of interactions between library branches informed us that potential solutions for visual navigation in a physical space should be customized per domain.

The observations informed us about common existing interactions at different library branches. To obtain more details on the ideas and motivations of library users, we proceeded with interviews.

\section{Interviews}

Ten semi-structured interviews were conducted with students in the UiO Science Library on 19th October 2016. The aims of these interviews were to find out why students were in the library, how often, what their activities in the library were, what else they thought they could do in the library, place preferences, and their knowledge about library services. 
Students were from a diverse set of studies, including Geosciences, Mathematics, Biochemistry, Physics and combined studies. Over half of the participants (six out of ten) were in the first year of their study, while the others in second to fourth year, and one in the sixth year. Most of the interviewees (eight out of ten) were very regular library visitors, going to the Science Library between four and six times per week, while two interviewees visited the library two to three times per week. In terms of their current activities, most students expressed that they were studying and working on assignments. Several students expressed that the library induced a "working mood", and gave a mindset to do homework. Thus, participants expressed the value of the physical environment, for instance for getting into the right mood for studying. One interviewee said that (s)he liked the "nostalgic value of books", with the feeling of being surrounded by them, and being able to "stare at the books" - even though (s)he didn't engage in any book lending yet. This has similarities with Blandford et al. (2006)'s study, in which users also indicated the importance of the physical surroundings and properties.

Two students also mentioned that they would relax from time to time in the library, for instance by chatting with friends or playing card games. One participant indicated that (s)he would at times engage in "browsing for interesting books", i.e. exploring. The interviews also showed that many students in early periods of their study were still "on the fence" with respect to using library services, for instance reflected by the fact that book lending was not very common in the group, with five participants indicating they had never done it (one student indicated that this was "not yet needed"). The more experienced students, in contrast, actually did borrow books. Some students indicated that they potentially could perform such activities as playing games, talking to friends, and going to events, but had not gotten around doing it yet.

From this study, we concluded that it could be worthwhile to engage some of the library users to use more of the opportunities in the physical library, in particular students in early stages of their study, for instance to start exploring available resources. For more advanced students, there should be possibilities to explore more different and varied books. We devised that digital browsing systems in a physical environment should be dynamic, engaging and inviting, with possibilities to stimulate curiosity and "surprise" among students.

To get a better overview of the usage of the digital library systems, available search logs were gathered.

\section{Search Log Analysis}

We analyzed the transaction logs of Oria, the discovery system in use at the University of Oslo Library, looking at popular user queries as well as queries resulting in zero results. The first analysis was done in October 2016, and the findings were presented internally. Subsequently, the research was presented at VIRAK, a Norwegian library conference, and further extended to a journal paper (see: Huurdeman, Aamodt, \& Heggø, 2018).

The first part of the final analysis "examined the nature of both popular and zero result searches in the discovery system at the University of Oslo by classifying them" (Huurdeman, Aamodt, \& Heggø, 2018). It was found that "popular user queries typically contain few words", and a prevalence of title queries for books, journals and databases. The zero result queries turned out to be different in nature: they "typically involve long queries, pointing to a more diverse set of materials, including journal 
articles, and in many cases consist of pasted reference citations." Another important finding was the high degree of curriculum-related queries ( $58 \%$ of the analyzed popular queries, and $28 \%$ of zero result searches), which has implications for supporting users within the library space. Subsequently, we investigated the success of the popular user queries, and found that query success is not guaranteed: $20 \%$ of the queries in the top 50 failed. We also observed that query popularity was varying over time, detecting "a distinction between queries popular at specific moments, for instance for reading list materials, and more regular queries occurring across time, including database queries." The third part of our analysis consisted of looking at the reasons behind zero result searches. The most common reasons for not getting any results were directly pasted citation references $(22 \%)$, and apparent spelling or reference mistakes (20\%).

In sum, our findings from the log analysis pointed to the importance of improving current digital library system features and metadata (as well as increasing users' information literacy). Also, the integration of curriculum materials ought to be achieved. For our project, the analysis provided valuable input in terms of real-world queries performed by actual users. The fact that a considerable degree of queries did not directly result in the right resource being found, shows us the limitations of current search systems in a library context. In our dataset, we also found many traces of exploratory queries, which urged us to further examine browsing opportunities.

Besides examining existing behavior in the library in the first three explorative studies, we intended to further think "out of the box" by conducting different brainstorms.

\section{Brainstorms}

Three brainstorms were organized in the context of the Visual Navigation Project: one was an open exploration of possibilities of future developments in the digital and physical library space (29.09.2016). Two later brainstorms (23.11.2016 and 30.11.2016) were focused on touch table use (for more details, see Huurdeman, 2017a). All three brainstorms were based on 6-3-5 brainwriting (Rohrbach, 1969), a structured brainstorming technique.

The first brainstorm was conducted with a Master student in Interaction Design, one of the paper authors, a recently employed librarian and an exhibition designer. This brainstorm resulted in over 40 open-ended ideas for future library developments. These ideas varied widely, and included navigation improvement (e.g. via guiding lights), integration of idea walls, adaptive lighting (e.g. spotlights on books that match your interest), personalized language courses, as well as various ideas for smartphone apps in a library context (including videos, live streams, chats and searching/ordering of resources).

The two later brainstorms were focusing on the use and usefulness of touch tables in the library. The first was conducted by a Master student in Interaction Design, together with a first year student, a newly employed senior librarian (Science Library), an experienced librarian (Science Library), and a Chemistry subject specialist. The second brainstorm was conducted by one of the paper authors, with an employee of the Humanities \& Social Sciences Library, one from the Medical Library, a Master student and a PhD student. Before the brainstorms, participants could take a look at the touch table, and try out a basic drawing application on the table. We deliberately did not show other applications, to not influence their ideas about potential touch table use. 
Together, both brainstorms resulted in over 75 ideas for possible usage of the touch table. These ideas were spatially clustered into groups of similar ideas, using the affinity mapping technique. In affinity mapping, written notes are spatially laid out on a surface, and subsequently clustered based on their affinity, i.e. "their similarity or relevance to a shared topic." (Harboe \& Huang, 2015). In our case, this resulted in seven main sets of ideas, summarized in Table 1: Exploration, Searching, Navigation, Discipline-centred, Collaboration \& Creation, Personalization, and Gaming \& Relaxation.

\begin{tabular}{|l|l|}
\hline Cluster & Sample ideas \\
\hline Exploration & "visually explore outer space", "explore human body", "explore citations" \\
\hline Searching & "visually grouping search results by hand, reorder and arrange", "searching based on author name" \\
\hline Navigation & $\begin{array}{l}\text { "Choosing a discipline and subject, get highlighted map with library materials", "maps of library } \\
\text { services", "map of things to do on campus" }\end{array}$ \\
\hline Discipline-centred & "Digital experiments (e.g. physics, chemistry, biology)", "physics simulations" \\
\hline $\begin{array}{l}\text { Collaboration \& } \\
\text { Creation }\end{array}$ & $\begin{array}{l}\text { "Creative lab - idea sourcing", "Creating art", "idea wall”, "collaborative space for group work", } \\
\text { "favorite book voting", "photo wall” }\end{array}$ \\
\hline Personalization & "Scan library card and get personalized info", "scan book to find related content" \\
\hline $\begin{array}{l}\text { Gaming \& } \\
\text { Relaxation }\end{array}$ & $\begin{array}{l}\text { "Quizzes", "Making music, build instruments and play them together", "drawing competition with } \\
\text { AI" }\end{array}$ \\
\hline
\end{tabular}

Table 1: Affinity mapping results, based on two open-ended brainstorms

Our touch table-focused brainstorms resulted in a very rich diversity of ideas for future developments in the physical library setting, as well as for the use of touch tables in the library. More traditional approaches in a digital and physical library setting, such as searching and navigation turned up, but also exploration, commonly associated with the physical library. Further ideas encompassed personalization, gaming as well relaxation, and collaboration \& creation. Many of these ideas could be better facilitated by the large touch table than by smaller devices, such as smartphones, tablets and regular computers.

\section{Integrating Digital Tools into the Physical Library Space}

The importance of the physical location of the library (Blandford, 2006), as well as its inherent affordances (Björneborn, 2008), and the outcomes of our explorative studies inspired us to experiment with actual digital devices, such as touch tables and large touch screens in the physical library space. We looked at how we can 'blend' these tools into the library environment, and how to improve connections between touch applications and events, physical collections, digital collections and external resources (see Figure 2). 


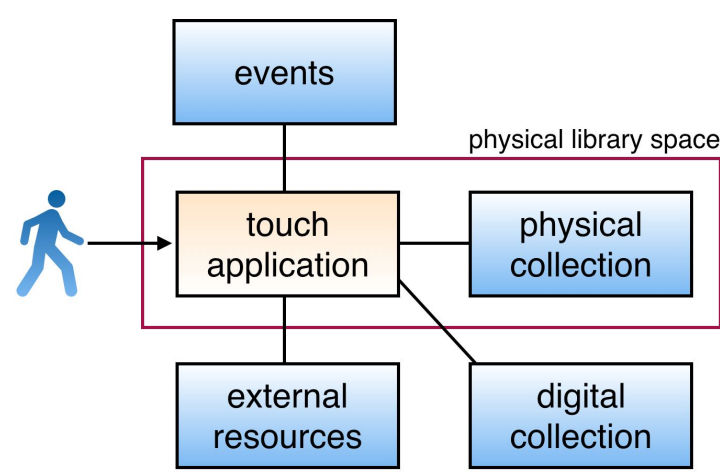

Figure 2: Touch applications, running on large touch screens, can potentially connect events, collections and resources inside and outside the library

Nine touch applications were developed in the context of the Visual Navigation Project between September 2016 and June 2018. Next, we describe six of the deployed applications. These applications can be divided into collection-centric and event-centric approaches.

\section{Collection-centric}

Three projects, carried out by students from the Department of Informatics supported by library staff, were focused on a specific collection: the Science Fiction collection of the UiO Science Library. This collection, with more than 9,000 books, is the largest public collection of Science Fiction books in Norway. ${ }^{1}$ The collection is housed in a specific space in the library, decorated with Science Fiction objects, and provides study and lounge sections, as well as films, series and games. Inspired by the fact that the Science Fiction collection and its whereabouts are still relatively unknown among library users across the University of Oslo, three projects to design and develop touch table applications were initiated.

The first Science Fiction touch application was created by three students for a Bachelor-level Interaction Design course at the university (Fall 2016), and the Science Library acted as the client for their project. The students carried out small-scale studies in the library, and created a touch table application to browse parts of the Science Fiction collection (specifically, 'Star Wars' and 'Doctor Who'). This application tries to engage passers-by by showing a pulsating screen with characters from the series, and encourages people to touch the screen. It contains a selection of library books, videos and games, but also information about characters in the series, as well as social media channels and events. The application was placed in the room housing the Science Fiction collection, and the students conducted an evaluation with two expert users and five students. Most feedback was positive, but also some usability issues came up, such as the placement of buttons on a large touch screen, and the students subsequently improved the application. In relation to the content of these types of applications, an issue of balancing emerged: for Science Fiction experts, the content may not be deep enough, while for novices a topic will need a suitable introduction (Huurdeman, 2016; Aamodt, 2017).

\footnotetext{
${ }^{1}$ http://www.ub.uio.no/english/libraries/ureal/ureal/collections/scifi/index.html
} 


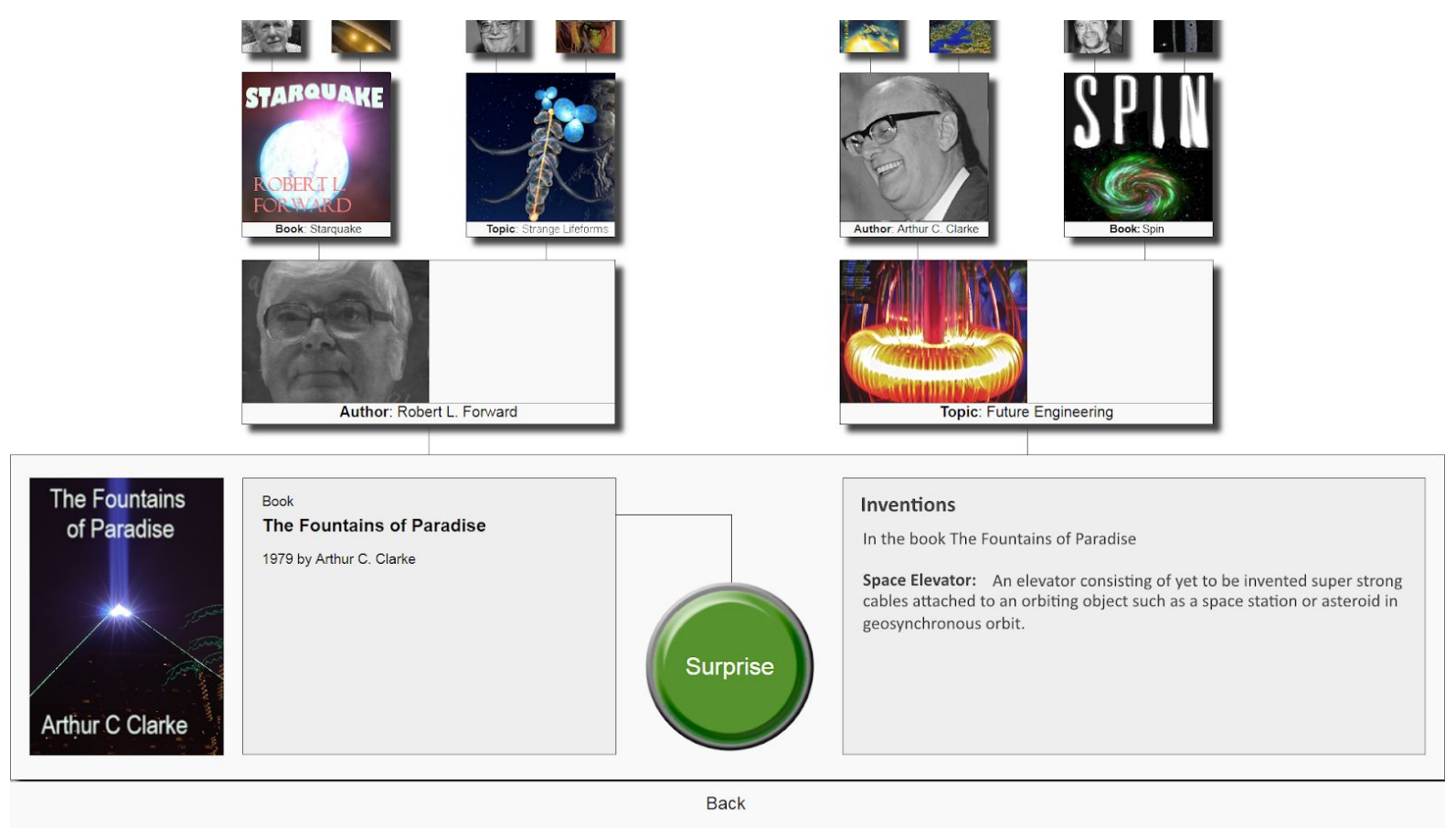

Figure 3: Screenshot of SciFi Explorer prototype

A second project, SciFi Explorer, aimed at inducing curiosity. It was inspired by some of the exploratory studies described in the previous section, and created in early Spring 2017. A student in Interaction design conducted his Master's project about how to create curiosity about Science Fiction in a touch table application (Okun, 2017). He performed a number of iterations with respect to design, prototyping and user testing, using a Design Thinking approach (Culén \& Gasparini, 2015). The student, in collaboration with technical and content specialists at the Science Library, created an application containing Science Fiction books (e.g. 2001: A Space Odyssey), authors (e.g. Isaac Asimov), keywords (e.g. Androids), and movies (e.g. Blade Runner) (for more information, see Huurdeman, 2017b). The application emphasizes exploration with its vertically sliding topics, as well as a large 'Surprise' button, located centrally in the interface (see Figure 3). Three types of surprises were tested: movie and book quotes, videos and actual touch-based games. These surprises were related to the topics selected by a user (for instance, a math game for a topic about Mathematics). By conducting a user study with six participants, the final application was evaluated. It showed some of the intricacies of creating an application to induce curiosity: for instance, one user that was disappointed with the initial surprise presented did not touch the surprise button again in the rest of the session. Most users however, had a more positive initial experience, interacted with the button at multiple moments in the session, and provided positive feedback on the application.

The third collection-centric project, Recomat, was conducted in Fall 2017. It focused on both community building and visualization of the collection. A group of four Bachelor-level Interaction Design students used design thinking to create a recommendation application, partially inspired by Pinterest (see also Thodesen, 2018). In early studies with library users, group members looked at obstacles between potential users and the collection. An issue of not knowing about the collection emerged, the issue of (lack of) time, as well as of the potentially daunting size of the collection. By creating a touch application, the students aimed at both increasing exposure of the collection, and eliminating the need for prior time-consuming browsing of the collection. To ease students encounters with the Science Fiction collection, the final application was focused on recommendations. It was 
created in four design iterations by the students and implemented by technical experts at the Science Library. The application brings the physical collection closer to the digital realm by allowing users to scan a physical book. The application recognizes the RFID tag attached to each book in the library, making it possible to directly recommend a (physical) book, to rate it and to choose the topics contained in a book. Other users can subsequently use the same application to browse the recommendations, see the book covers, short descriptions, ratings and categories. The application also displays the 'book of the month' and makes it possible to browse recommended books by category (e.g. Action, Horror, Crime and Science). The final prototype was evaluated with students by the project group in a summative usability test, which showed that the application was intuitive and user friendly, but with a lower score on a question if the application would be used frequently. The project group surmised that the participants understanding of 'used frequently' could be biased by comparison with apps that have very high usage, such as Facebook and other social media apps. After further development and refinement by employees of the Science Library, this application has been placed on a touch screen in the Science Fiction collection's room, and a simplified version was placed in the main reading room of the library.

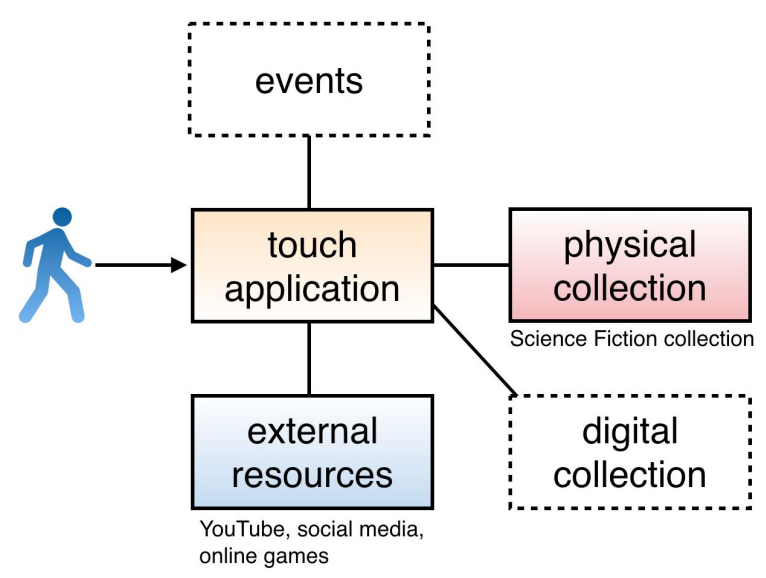

Figure 4: Collection-centric applications created in the context of the Visual Navigation Project

Figure 4 summarizes the three discussed collection-centric applications. They connected the physical library with a large physical collection, which could be daunting to approach for newcomers, and tried to tease curiosity about this collection. The various applications also provide connections to related resources, such as YouTube videos, social media, and online games. Moreover, one of the applications even made it possible to scan physical books to access digital features. Thus, the apps showed an integrative approach to physical and digital content. In future applications, this can be extended to other collections beyond the physical Science Fiction collection.

Next, we discuss how applications can be inspired by events occurring in- and outside the library space.

\section{Event-centric}

The three event-centric applications to be discussed here were designed and developed internally at the Science Library, using the interactive media framework XIMPEL ${ }^{2}$. These applications were meant as alternating, short-term exhibitions within the library space, usually for a few weeks (see table 2), as

\footnotetext{
${ }^{2}$ XIMPEL is available at http://ximpel.net. Our extensions to the framework for usage in a kiosk context can be found at https://github.com/scriptotek/ximpel-kiosk-tools.
} 
opposed to the collection-centred applications, which potentially could be exhibited for longer periods of time.

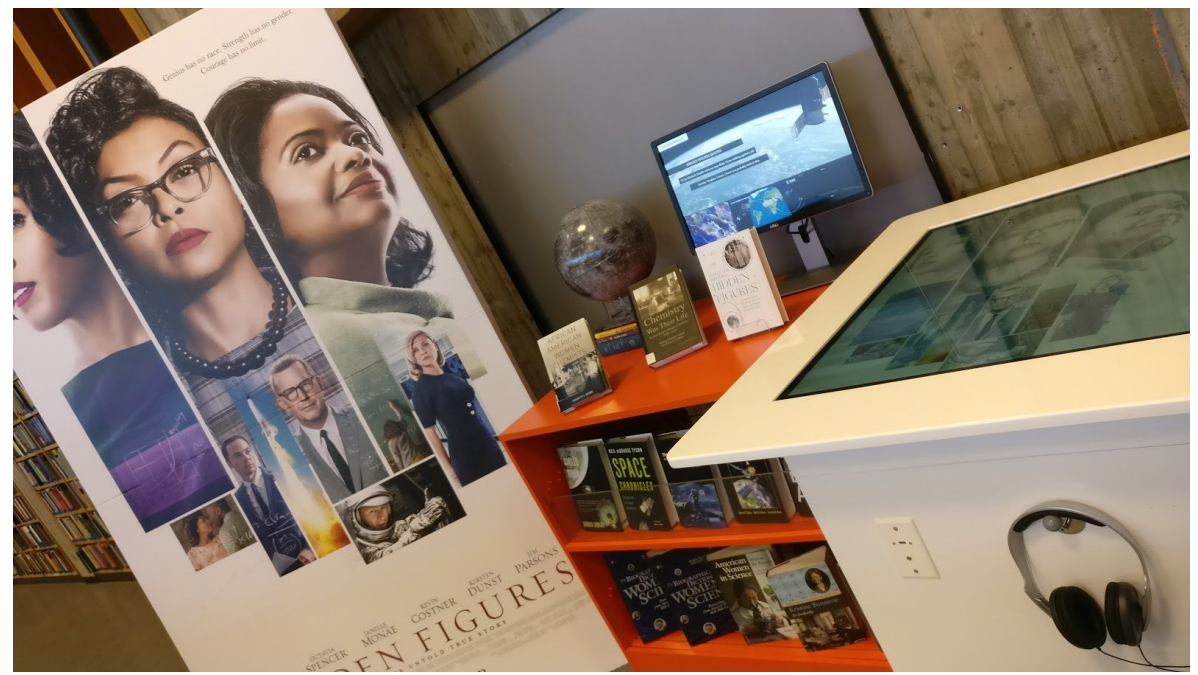

Figure 5: Hidden Figures exhibition, with movie materials, physical books, a screen with images from the International Space Station with overlaid movie quotes, and the touch table application.

The first of the projects was related to an event with a pre-screening of the movie Hidden Figures, which took place in March 2017 in the UiO Science Library. This movie, based on the book with the same name, recounts the untold story of the real-life female mathematicians behind the NASA space programme. The touch table application was created as part of an exhibition about the movie in the library, and aimed at marketing the pre-screening, and at connecting library materials with the movie (see Figure 5). Fox Pictures provided promotional materials and clips from the movie, while librarians selected relevant materials to include in the application. The final application contained film clips, books, and information about the characters in the movie. Most books could be read via a touch-based on-screen reader. As a first step, tests of the application were conducted with library staff, which helped to optimize the application. For instance, users indicated that they would like to "take away" materials from the table, so we included shortened bit.ly links to materials to facilitate e-book downloads on the university campus. Furthermore, this was the first time that we installed a touch application in the main reading room of the library, and left it unattended. Thus, this provided us with more experience of using digital applications in a physical library space. To take a practical example, upon installation of the table, some passers-by just looked at the table, but did not interact with it. Therefore, we attached a small "touch me" note to the table, which resulted in more interactions, and we more explicitly incorporated this into the design of later applications.

For this application, we also created a framework for capturing user interactions ${ }^{3}$. This framework helped us to evaluate (unattended) use of the application, so we gained insights into how an application in the physical library space would be used. For the first two weeks of installation, we looked at the depth of exploration of the application (see: Huurdeman, 2017c). We observed that 70 users $(53 \%)$ only selected one video, book or movie information screen, while 62 users (47\%) looked at 2 or more screens. Of this group, the most active users (14\%) explored 4 to 14 screens. Second, we looked at the most used media types: books were most popular, followed by movie fragments and character information screens. Also, we found that the time spent per material type (for screens having

${ }^{3}$ https://github.com/scriptotek/microticks 
at least 10 views), was 30 seconds on e-books, followed by 28 seconds on movie-fragments. Finally, we looked at the use of the application over time. This led to some interesting insights: we observed that most sessions with the application occurred in the late afternoon (between 16:00 and 17:00). By capturing usage statistics, we were also able to detect usability issues. For instance, by generating heatmaps such as the one in figure 6, we could observe that people sometimes clicked in places where there was nothing to interact with, helping us to improve the design. Moreover, we found that combining both readable e-books and descriptions of physical books caused confusion, leading users to try to swipe in the representations of physical books - despite an included description that it concerned a physical book available in the adjoining exhibition. This led us to replace the physical books listed in the application with e-books, after the first two weeks of use.

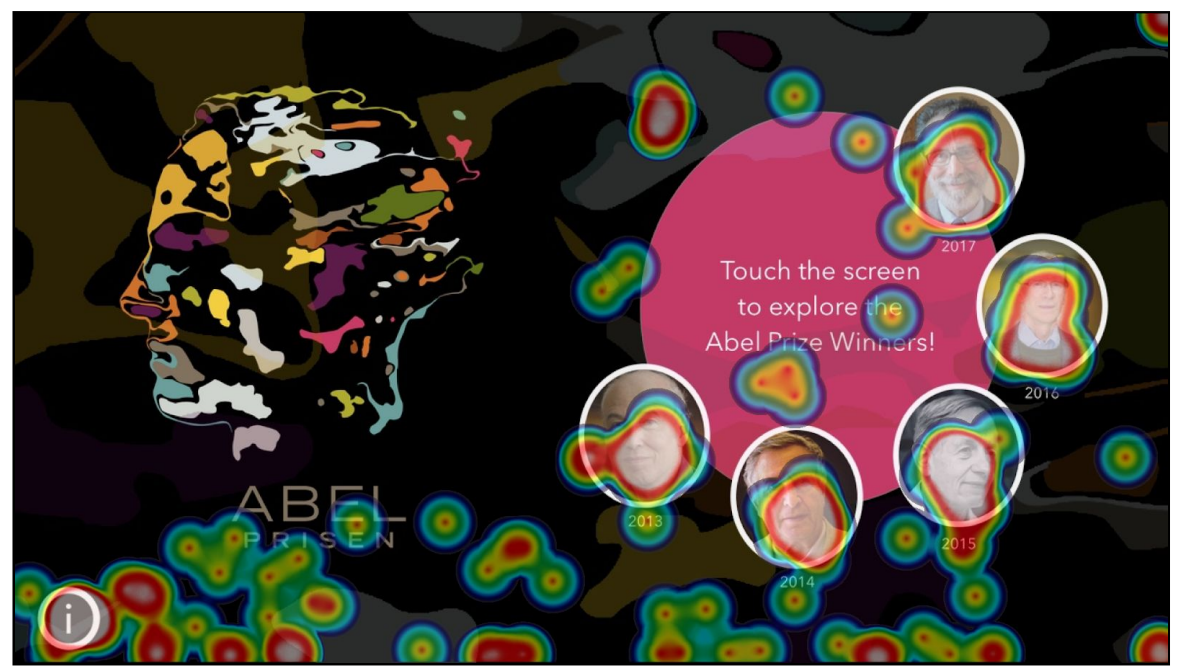

Figure 6: Heatmap showing common interactions on the main screen of the Abel Prize application.

A second event-related application was made for the Abel Prize, a prestigious prize in the field of mathematics awarded by the Norwegian Academy of Science and Letters. The touch table application, placed in the foyer of the building that houses the Science Library, made it possible to explore the Abel Prize winners of the last five years, to find related e-books, scientific articles and videos, and to encounter background information about the Abel Prize (see: Huurdeman, 2017d). The application was designed taking into account the lessons learned during the development of previous applications. This included using a higher degree of animated content, a simplified navigation structure (including a clear initial "attract screen"), swipe navigation support, and the inclusion of e-materials, as well as ways to view encountered material on users' own devices. After some initial testing, we deployed the application in the library and again gathered statistics. We found some similar tendencies as for Hidden Figures, for instance that most sessions with the application occurred in the afternoon, in this case 15:00 and 16:00. The most visited screen was about the current year winner of 2017, and the most viewed items were also included on that screen: a news article, a video about the announcement, and an article written by the latest prize winner. We also extended the logging capacities, and were able to determine how engaged people were with articles and e-books. For the whole period of deployment, 97 users (33\% of all users) opened these materials, exploring between 2 and 62 pages (12.72 pages on average). 
A third application was built around a conference organized at the University of Oslo, the Biokonferansen (Bio Conference) 2017 . Like the previous Abel Prize application, the touch table containing the application was placed in the foyer of the library, where a social event of the conference took place. The theme of the application was the celebration of the 50th anniversary of the discovery of endosymbiosis, and contained information about the concept of endosymbiosis, animations and videos, as well as related articles and e-books. In this case, the screen opened most often was an information screen explaining the concept of endosymbiosis (141 views), and a screen with related videos, created locally and by the national broadcaster NRK (126 views). The most viewed media item was an introductory video about endosymbiosis (20 views).

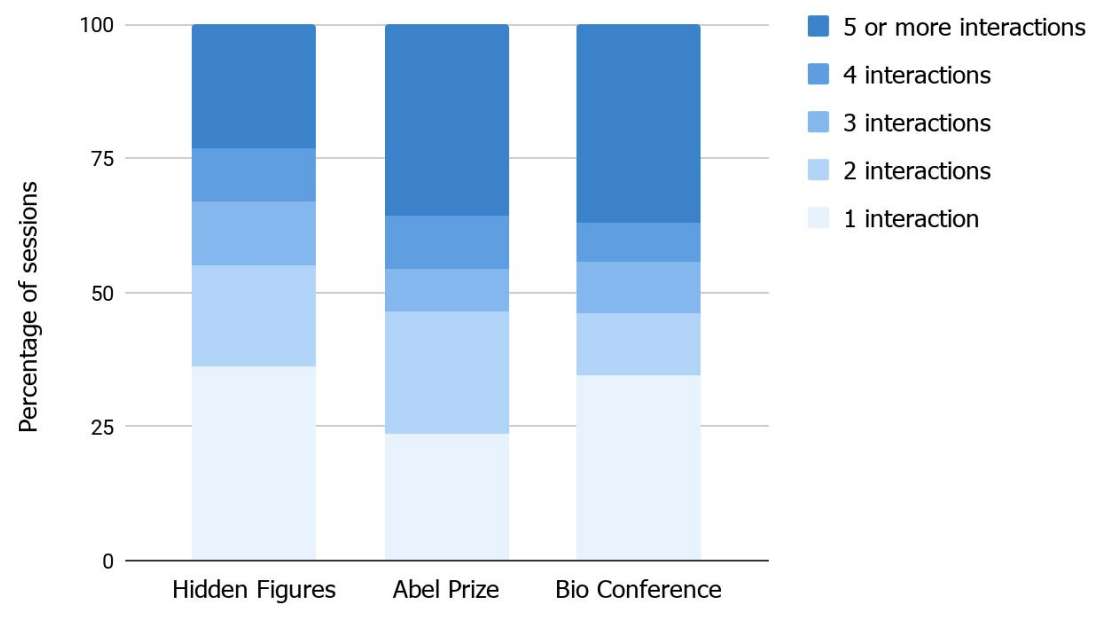

Figure 7: Chart comparing the number of interactions per user session of the Hidden Figures, Abel Prize and Bio Conference applications.

\begin{tabular}{|l|l|l|l|l|l|}
\hline Name & Content & $\begin{array}{l}\text { Placement (num. } \\
\text { of weeks) }\end{array}$ & $\begin{array}{l}\text { Total } \\
\text { number of } \\
\text { sessions }\end{array}$ & $\begin{array}{l}\text { Sessions } \\
\text { in first 2 } \\
\text { weeks }\end{array}$ & $\begin{array}{l}\text { Mean num. content } \\
\text { screens opened } \\
\text { (first 2 weeks) }\end{array}$ \\
\hline Hidden Figures (1) & $\begin{array}{l}10 \text { screens, } 33 \\
\text { media items }\end{array}$ & $\begin{array}{l}\text { Reading room } \\
(5 \text { weeks) }\end{array}$ & 245 & 167 & $3.74(3.88)$ \\
\hline Abel Prize (2) & $\begin{array}{l}7 \text { screens, } 20 \\
\text { media items }\end{array}$ & $\begin{array}{l}\text { Foyer } \\
(4 \text { weeks) }\end{array}$ & 291 & 159 & $5.2(5.01)$ \\
\hline Biokonferansen (3) & $\begin{array}{l}5 \text { screens, } 14 \\
\text { media items }\end{array}$ & $\begin{array}{l}\text { Foyer } \\
(4 \text { weeks) }\end{array}$ & 154 & $91^{5}$ & $6.27(7.12)$ \\
\hline
\end{tabular}

Table 2: Usage statistics for all three event-centric applications

Table 2 summarizes the usage of the three event-based applications. As can be seen, the applications attracted a considerable number of users, reflected in the number of sessions - we count sessions here, since we cannot discern from the usage data how many persons used the application at the same time. It can also be observed that, paradoxically, statistics show that users look at more screens in application (2) and (3), even though the applications feature less content. We hypothesize that this is due to the simplified navigation, i.e. menus with less depth and more breadth, directly accessible from the initial 'attract screen' and via swiping. This appears to be encouraging people to explore more

\footnotetext{
${ }^{4}$ http://www.bio.no/index.php/biokonferansen/bio-konferansen-2017

${ }^{5}$ Logs are unavailable for the initial three days due to a technical issue
} 
screens instead of less screens. This is further contextualized in Figure 7, which shows the depth of interaction. Application (2) and (3) clearly result in more deep interactions. We will further investigate this in future work.

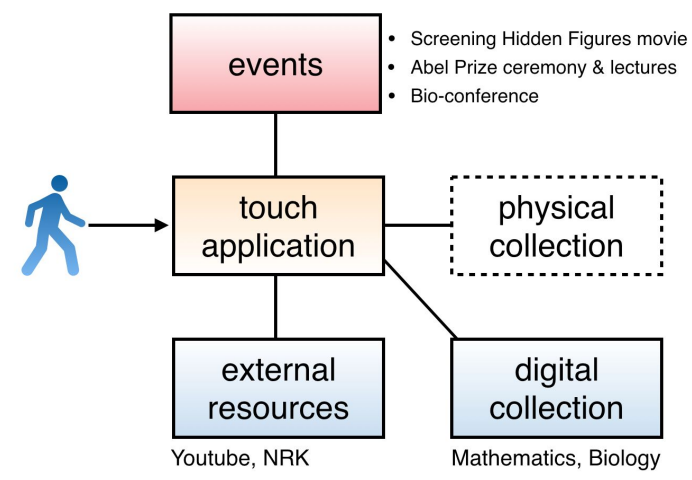

Figure 8: Event-centric applications created in the Visual Navigation Project

Finally, Figure 8 summarizes the event-centred applications. In this case, they connected events, digital collections, as well as external resources, in particular videos. The specific disciplines of each application (Mathematics and Biology), inspired us to combine both introductory and advanced sources in the applications, so they would have value for persons with different levels of knowledge. The usage statistics show a considerable number of users interacted with the application, and thus were potentially able to find relevant new resources from the normally unexposed digital parts of the library.

Towards integrative approaches

The collection and event-centric approaches show what can be achieved by incorporating touch screens into the library environment. Further work in the Visual Navigation Project is carried out towards more hybrid and integrative approaches.

Within our CollectionXplorer prototype, we are creating visualizations drawing data from the whole collection of the library, with the possibility to use these in an event-based context. For these approaches, we are inspired by the rich metadata available for the library collections, including subject headings and classification data. This allows for wide-ranging possibilities in terms of visualization and visual navigation. We were also inspired by recommendations about digital book browsing systems by McKay et al. (2017). Specifically, enabling multiple points of collection access, supporting zooming capabilities, seamless transitions, placemarking support and accessing the relevant book information. We also took inspiration from Hinrichs (2013) assertion, in the context of exhibition spaces, that "visual overviews can act as entry points" for exploration, and that "interlinking visually and conceptually distinct visualizations that present the same set of information from a variety of perspectives" (p.287) can promote serendipitous discoveries and potentially address diverse audiences. From our own experiments, we also derived the importance of pinpointed content for the users of the applications. This relates to the idea of Björneborn (2008) that a user approaches library services from their own socio-cognitive context. 


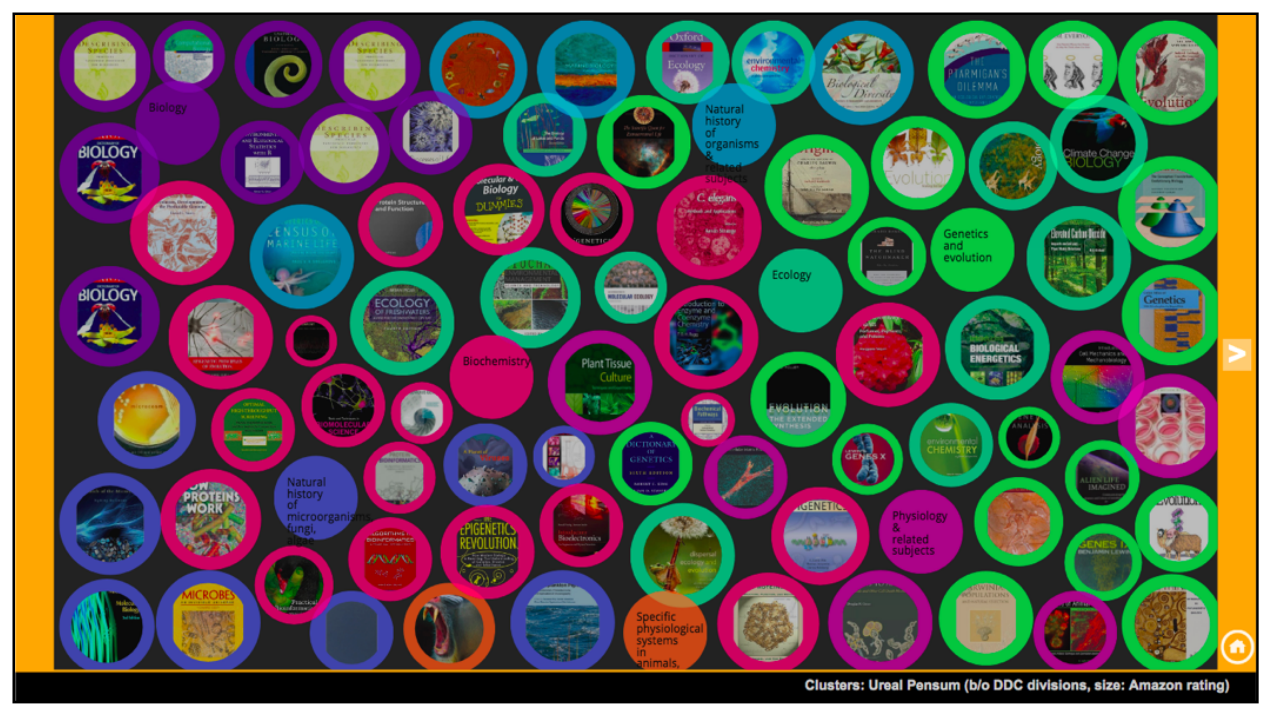

Figure 9: Sample cluster-based visualization in the CollectionXplorer prototype, allowing for browsing books and filtering these based on Dewey Decimal Classification categories. The size of items pertains to their Amazon rating.

To achieve our vision, we have merged catalog records with Amazon data, and used the D3 ("Data-Driven Documents") framework ${ }^{6}$ to create six types of interactive visualizations for initially 300,000 books. These visualizations entail interactive charts (1), force-directed diagrams (2), word clouds (3), maps (4), scatterplots (5), and cluster diagrams (6), which can be dynamically switched at any moment (an example is provided in Figure 9). The application allows for 'liking' items encountered along the way, as an interpretation of the aforementioned 'placemarking' support. Currently, we are refining our prototypes and will perform a study of their utility. Our approach aims to use personalization for providing pinpointed materials for the user in question, by utilizing RFID-based (library) cards and library resources, such as books. This can be based on a user's socio-cognitive context, for instance academic discipline, indicated interest or level of study. By connecting this context to physical and digital collections, external resources and events, this provides a more integrative approach to the incorporation of touch devices in a physical library space (see Figure 10).

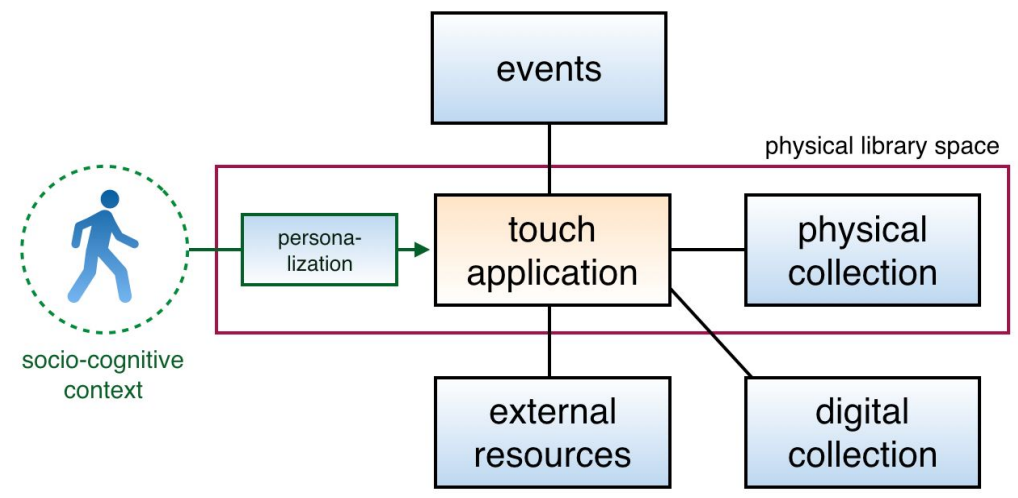

Figure 10: Towards an integrative approach, incorporating personalization (based on a user's socio-cognitive context) and different types of events and (library) resources in a single touch application.

\footnotetext{
${ }^{6}$ https://d3js.org/
} 


\section{Discussion}

The explorative studies and experiments with integrating digital tools in the physical library space have led to a number of learned lessons, which we discuss in this section.

First of all, there is the value of explorative user studies to gain new and relevant ideas. Inspiration can be sought from previous literature, as well as current physical and digital library use, for instance via observations, surveys and query analyses. Thinking "out of the box" can be achieved via open-ended user studies. For instance, in the Visual Navigation Project we conducted brainstorms, gigamapping, as well as interviews. By using these open-ended approaches, it is possible to explore alternate methods towards access to library resources.

Second, there is the importance of data, both in terms of traditional metadata, as well as usage data. Metadata forms a key element of any (digital) library, but some available data is rarely used for access in a digital library context. For instance, subject vocabularies, classifications and external metadata (e.g. from Wikidata) often do not play a major role in current library catalogs, but have shown to be useful in the visual approaches in the Visual Navigation Project. In addition, usage data can also improve offerings by the library. In this paper, we have shown the value of anonymous transaction logs, originating from discovery systems and library catalogs, but also of analytics within custom-made tools. By using cautious approaches, i.e. capturing data which is fully anonymous and cannot be traced back to single users, one can generate insights to improve applications. This can be at level of usability and navigation, but also at the level of shown content.

Third, collaboration at different levels is of key importance. The Visual Navigation Project had a relatively small project team in terms of FTEs, but could benefit from various active collaborations. The 'in-house' collaborations were for instance with subject specialists (suggesting and editing application content, including descriptions, books and articles), event organizers (providing event assets and suggesting placement of the touch table) and designers (providing design assets). In addition, we collaborated with the Informatics department, which allowed us to propose projects which could be conducted by Bachelor and Master students following Interaction Design courses (see also Culén \& Gasparini, 2015). These collaborations have resulted in a wide variety of applications in prototype form, which could be extended and used within the library.

It is also important to do community building, in terms of project outreach as well as expertise. During the project, we regularly updated the website, which included news items and weekly progress reports, so people within and outside the University of Oslo Library could continuously follow our progress. In addition, we shared the source code of all our experiments and applications on Github, as well as used data - if possible due to privacy and copyright reasons. Via meetups and workshops we discussed project ideas and progress, and we organized workshops to teach visualization skills, but also the creation of touch applications to others. The project also used a pragmatic approach to speedup design and development. If needed, we bought modules for our touch applications (such as an on-screen, touch-based book reader), and we used and extended existing open-source frameworks as much as possible (such as the interactive media framework XIMPEL). 
Further, we would like to emphasize the importance of the user experience, and of doing extensive testing of applications in advance. For instance, initial tests can be performed with colleagues, or with "guerilla tests" in the library space, followed by more formal user studies in later stages. It does not stop there, either: after the deployment of a touch application, it is very worthwhile to monitor usage and possibly occurring issues. For instance, the deployment of our touch applications suggested that simplifying application structure led to increased depth of application use.

Finally, content remains a point of concern. First, this entails appropriately dynamic content. The more static, event-centric touch applications described in this paper were only shown a few weeks each to reduce potential fatigue. A frequent shifting of applications was conducted to retain curiosity in both the applications and the touch table as an interactive medium. Another approach to dynamic content would be to explore a more data-driven design, as touched upon in the integrative experiments. Second, relevant content for a target group is needed - for instance based on a student's academic discipline and year of study. In this paper, we proposed an approach utilizing personalization based on a user's socio-cognitive context (as defined by Björneborn, 2008), to further customize content shown to a user. Third, an important challenge with respect to content is to optimize for the 'first interaction'. There is a risk that disappointing first impressions when approaching a new touch device in the library can result in users abandoning the device and not return. We suspect that the quality of an "attract screen" plays a major role in whether the user proceeds to investigate an application or not. In future work, it would be interesting to examine this using $\mathrm{A} / \mathrm{B}$ testing and proximity sensing to measure the baseline of potential users.

\section{Conclusion}

This paper has looked at ways to bridge the gap between the visual experience of browsing physical and digital academic library environments. The main focus of this paper was on integrating digital browsing and exploration tools into the physical library.

Initial explorative user studies in the Visual Navigation Project revealed several opportunities to engage and encourage library users to use more services. Further brainstorms uncovered the potential of using large touch-based devices in physical libraries, such as touch tables.

Three different types of applications were created to gather experience with the use of touch tables in a library context. Collection-centric touch table applications, focusing on a collection of Science Fiction, were created to ease access and induce curiosity and knowledge of the collection and contribute to community building. Event-centric applications, on the other hand, were created to connect events with digital library collections and external resources. We demonstrated how creating effective applications requires careful balancing with respect to user experience and included content. Although such optimization requires effort, the good news is that these kinds of applications do not necessarily need a lot of content. We found that a careful selection of a few good resources works better than an abundance of resources. We also found that books were just as, or more, engaging than video clips, but since it is rather unlikely that users will read a whole e-book on a touch table, there need to be options for users to "bring the resources with them", for instance by scanning their student card to get an email with the link to an e-book, or just by providing a short URL to retrieve it. Moreover, usage data turned out to be of high value for iteratively improving these applications at the navigation and content level, ultimately resulting in higher user engagement. 
Finally, we discussed the need for novel integrative approaches, utilizing personalization based on users' socio-cognitive context, as well as interactive, data-driven visualizations to entice and engage library visitors to utilize relevant parts of the full library collection. Future work includes the further deployment and testing of these integrative approaches in the physical library space, but also the integration of these visual browsing tools into the digital library environment. This way, in the words of one our workshop participants, we may take the next steps towards the 'library of our imagination'.

\section{Acknowledgements}

This paper was created in the context of the Visual Navigation Project (http://www.ub.uio.no/om/prosjekter/the-visualisation-project/), conducted at the University of Oslo Library, in collaboration with the Department of Informatics and by support of the National Library of Norway. The authors would like to thank project members Live Rasmussen, Helge Mjelde, Brit Heidi Rustad and Nina Marie Thodesen. Also, our acknowledgements go out to Alma Culén, Andrea Gasparini, as well as Yaron Okun and all other students involved in the described projects. With respect to help with datasets, we would like to thank Vu Tran, and Winoe Bhikharie for assistance with extending the XIMPEL framework for touch applications.

\section{ORCID}

Hugo Huurdeman http://orcid.org/0000-0002-3027-9597

Dan Michael Heggø http://orcid.org/0000-0002-6189-5958

Mikaela Aamodt http://orcid.org/0000-0003-4010-3728

\section{References}

Aamodt, M. (2017). "Royal approval” of a SciFi Touch Table Application. Retrieved from http://www.ub.uio.no/om/prosjekter/the-visualisation-project/news/royal-approval.html

Allen, S., \& Gutwill, J. (2004). Designing With Multiple Interactives: Five Common Pitfalls. Curator: The Museum Journal, 47(2), 199-212.

Bates, M. J. (2007). What is browsing — really? A model drawing from behavioural science research. Information Research, 12(4), 330.

Björneborn, L. (2008). Serendipity dimensions and users' information behaviour in the physical library interface. Information Research, 13(1), 370.

Blandford, A., Rimmer, J., \& Warwick, C. (2006). Experiences of the library in the digital age. Third International Conference "Cultural Convergence and Digital Technology". Athens, November 2006.

Culén, A. L., \& Gasparini, A. A. (2015). HCI and Design Thinking: Effects on Innovation in the Academic Library. Proceedings of the International Conferences on Interfaces and Human Computer Interaction 2015, Game and Entertainment Technologies 2015 and Computer Graphics, Visualization, Computer Vision and Image Processing 2015. (pp. 3-10). Lisbon: IADIS Press. 
Ford, N. (1999). Information retrieval and creativity: towards support for the original thinker. Journal of Documentation, 55(5), 528-542.

Harboe, G., \& Huang, E. M. (2015). Real-World Affinity Diagramming Practices: Bridging the Paper-Digital Gap. CHI '15. Proceedings of the 33rd Annual ACM Conference on Human Factors in Computing Systems (pp. 95-104). New York, NY: ACM.

Hinrichs, U. (2013). Open-Ended Explorations in Exhibition Spaces: A Case for Information Visualization and Large Direct-Touch Displays (Doctoral dissertation). University of Calgary, Calgary. Retrieved from http://dx.doi.org/10.5072/PRISM/27202.

Huurdeman, H. C. (2016). Darth Vader in the Science Library - Experimenting with a Touch Table in a library setting. Retrieved from http://www.ub.uio.no/om/prosjekter/the-visualisation-project/news/darth-vader-in-library.html.

Huurdeman, H. C. (2017a). Brainstorming Touch Table Use. Retrieved from http://www.ub.uio.no/om/prosjekter/the-visualisation-project/news/brainstorming-touch-table.html.

Huurdeman, H. C. (2017b). Designing for Curiosity in a SciFi Touch Table Application. Retrieved from http://www.ub.uio.no/om/prosjekter/the-visualisation-project/news/designing-for-curiosity.html.

Huurdeman, H. C. (2017c). Hidden Figures - Revealing Untold Stories Via A Touch Table Application. Retrieved from http://www.ub.uio.no/om/prosjekter/the-visualisation-project/news/explore-hidden-figures.html.

Huurdeman, H. C. (2017d). Engagement with the Abel Prize via a Touch Table App. Retrieved from http://www.ub.uio.no/om/prosjekter/the-visualisation-project/news/abel-prize-app.html.

Huurdeman, H. C., Aamodt, M., \& Heggø, D. M. (2018). "More than Meets the Eye" - Analyzing the Success of User Queries in Oria. Nordic Journal of Information Literacy in Higher Education, 10(1), $18-36$.

Huurdeman, H. C., \& Kamps, J. (2014). From Multistage Information-seeking Models to Multistage Search Systems. Proceedings of the 5th Information Interaction in Context Symposium, IIiX 2014, (pp. 145-154). New York, NY: ACM.

Kleiner, E., Rädle, R., \& Reiterer, H. (2013). Blended shelf: reality-based presentation and exploration of library collections. CHI'13. Conference on Human Factors in Computing Systems Proceedings (pp. 577-582).

Marchionini, G. (2006). Exploratory Search: From Finding to Understanding. Communications of the ACM, 49(4), 41-46.

McKay, D., Buchanan, G., \& Chang, S. (2015). Tyranny of Distance: Understanding Academic Library Browsing by Refining the Neighbour Effect. In Research and Advanced Technology for Digital Libraries (pp. 280-294). Cham: Springer. 
McKay, D., Chang, S., \& Smith, W. (2017). Manoeuvres in the Dark: Design Implications of the Physical Mechanics of Library Shelf Browsing. Proceedings of the 2017 Conference on Human Information Interaction and Retrieval (pp. 47-56). New York, NY: ACM.

Okun, Y. (2017). Design for nysgjerrighet: hvordan gjøre realfagstudenter nysgjerrige på science fiction? [Design for Curiosity: How to make science students curious about science fiction?]. University of Oslo, Oslo (Master's Thesis). Retrieved from https://www.duo.uio.no/handle/10852/57441.

Pearce, J., \& Chang, S. (2014). Exploration Without Keywords: The Bookfish Case. In Proceedings of the 26th Australian Computer-Human Interaction Conference on Designing Futures: The Future of Design (pp. 176-179). New York, NY: ACM.

Pickard, A. J. (2007). Research Methods in Information. London:Facet Publishing.

Pomerantz, J., \& Marchionini, G. (2007). The digital library as place. Journal of Documentation, 63(4), 505-533.

Rohrbach, B. (1969). Kreativ nach regeln. [Creative after rules]. Absatzwirtschaft 12, 73-75.

Sevaldson, B. (2011). GIGA-Mapping: Visualisation for complexity and systems thinking in design. Nordic Design Research, 0(4).

Thodesen, N. (2018). Recommendation Station - Visualizing the Science Fiction Collection and Community Building. Retrieved from http://www.ub.uio.no/om/prosjekter/the-visualisation-project/news/recommendation-station.html.

Thudt, A., Hinrichs, U., \& Carpendale, S. (2012). The Bohemian Bookshelf: Supporting Serendipitous Book Discoveries Through Information Visualization. In Proceedings of the SIGCHI Conference on Human Factors in Computing Systems (pp. 1461-1470). New York, NY: ACM.

Waugh, S., McKay, D., \& Makri, S. (2017). "Too Much Serendipity”: The Tension Between Information Seeking and Encountering at the Library Shelves. In Proceedings of the 2017 Conference on Conference Human Information Interaction and Retrieval (pp. 277-280). New York, NY: ACM.

White, R. W., \& Roth, R. A. (2009). Exploratory Search: Beyond the Query-Response Paradigm. San Rafael, CA: Morgan \& Claypool Publishers. 